\title{
Creating a Competitive Edge With Faculty and Curriculum Development
}

\author{
Melissa J. Dark \\ Dennis R. Depew \\ Robert J. Herrick \\ Purdue University
}

\section{$\underline{\text { Introduction }}$}

The United States has always enjoyed a high standard of living compared to the rest of the world. There are several ostensible reasons for this high standard of living. Our nation is able to generate employment opportunities, which provide an income to support our standard of living. The employment opportunities which provide these above average wages are usually found in the areas of manufacturing. Furthermore, the higher incomes in manufacturing are usually identified with what we term high-tech manufacturing.

These technically related jobs are directly linked to our system of higher education. Community colleges and universities provide technology related education programs for students who will eventually work in these industrial enterprises.

As a result of a national concern regarding our standard of living, which is linked to our ability to provide manufacturing jobs for our citizens, the federal government has created many new programs in the past decade to promote educational programs to support our industrial economy. The National Science Foundation established the Advanced Technology Education Program (ATE) to fund and support educational initiatives in the areas of mathematics, science, engineering, and technology education.

The Midwest Center for Advanced Technology Education (MCATE) at Purdue University is supported by the National Science Foundation. MCATE is a consortium between Purdue University and seven midwestern community colleges. The mission of MCATE is to enhance the educational opportunities and experiences available to students pursuing manufacturing related careers. The consortium is accomplishing this mission through faculty and curriculum development. This paper will focus on the planning, implementation, and evaluation process of the faculty and curriculum development activities supported by MCATE.

\section{$\underline{\text { Planning Faculty and Curriculum Development }}$}

MCATE subscribes to two basic tenets. The first is that faculty cannot teach what they do not know. As technology continues to change at a prodigious rate, technology faculty must remain 
current in their respective disciplines. If they do not stay current, then obviously they are merely teaching content which will provide little use to the students they serve. This will ultimately result in a poorly prepared technical work force unable to compete in the international manufacturing community.

A major corollary to the tenet of helping faculty develop their technical knowledge is that faculty members may possess excellent technical knowledge, but not have the necessary teaching skills to share their experience and knowledge effectively with their students. The typical technology faculty member often arrives at the first academic appointment with little formal preparation in fundamental pedagogical techniques or teaching methodologies. Therefore an effective faculty development program should provide opportunities for developing and enhancing teaching skills, as well as enhancing technical knowledge.

The second major tenet, which guides the activities of the Center, is the development of contemporary curriculum materials to support technology education. As faculty members learn new technology, they must translate this new information into materials which can in turn be used to teach their students. These curriculum materials may come in the form of student activities, lectures, laboratory assignments, demonstrations, or projects. Another major component of a curriculum development activity may come in the form of a new methodology of teaching.

With these basic tenets and a vision to help students, the staff of MCATE and their partners (Elgin Community College, Triton Community College, Parkland Community College, Macomb Community College, St. Louis Community College, Cincinnati State Technical and Community College, and Vincennes University) embarked on a journey to plan the 1997 workshop series.

In the fall of 1996, the MCATE staff and partners met to identify the topics and titles, and establish the dates for each workshop. A decision was made at the time of writing the proposal that offering the faculty development workshops during the summer would be best for most faculty. Offering the workshops during the summer would not conflict with semester teaching schedules, spring breaks, and holidays. At this planning meeting the following workshop titles were selected for the MCATE 1997 Summer Workshop Series.

MCATE 1997 Workshop Series

- Introduction to Visual BASIC for Technology

- Fundamentals of Rapid Prototyping

- Introduction to CAD/CAM Integration

- Applications of Cutting Tools in Manufacturing

- Understanding and Using Automatic Data Capture Technology

- Introduction to Programmable Logic Controllers

- Tools and Techniques for Maximizing Your Instructional Presentation

- The Art and Technology of Teaching Technology 
These workshop topics were identified relying on the knowledge and expertise of the MCATE partners. In identifying the titles for the 1998 workshop series, MCATE conducted a needs assessment to validate the need for the workshops. This needs assessment involved surveying technology faculty and industry representatives.

Validating the need for workshop topics is an important and useful exercise for several reasons, the first of which is accountability to the organization funding the activity. In the case of MCATE, the funding organization is the National Science Foundation. Another reason, which is equally important, is to insure that the subject matter presented to technology faculty enhances the educational opportunities of the students we all ultimately serve.

All of the 1997 workshops were developed utilizing a four-day format. The first three days were devoted to providing a positive learning experience for the faculty members attending the workshops. The faculty participants were selected from secondary schools, community colleges, and universities. These workshop participants were engaged in learning new technology, new pedagogical methodologies, and in some cases, both. The fourth day, which was scheduled to take place at least three months after the initial workshop, was designed to allow participants the opportunity to share with their colleagues how they implemented the knowledge gained from the workshop.

As a result of the fourth day, the curriculum materials developed by individual faculty members could be shared with MCATE as well as all workshop participants. This material can now be further developed for future workshops and disseminated to others interested in the subject matter.

\section{$\underline{\text { Recruitment and Implementation }}$}

Direct mailing, use of the World Wide Web, and List Servs, and word-of-mouth recruited faculty participants for workshops. When faculty members inquired about a specific workshop, they were sent the following information regarding participation.

1. An overview of the content of the workshop

2. Prerequisite knowledge or experience required

3. The date and location of the workshop

4. Background of the workshop leaders

5. Expectations regarding curriculum development and implementation

Each faculty participant was provided a $\$ 500$ stipend to defray costs associated with the workshop. This could include travel expenses as well as food and lodging expenses. Faculty participants were not charged a conference or workshop fee. The direct costs of the workshop were supported by MCATE. 


\section{$\underline{\text { Evaluation }}$}

The evaluation plan includes both formative and summative evaluation conducted by internal and external evaluators with regard to MCATE operating procedures, products, and services. Evaluation results are used formatively for continuous improvement and summatively to gauge impact. The fundamental question that is to be answered through the evaluation process is, "Are we achieving our goals?" The MCATE goals are as follows.

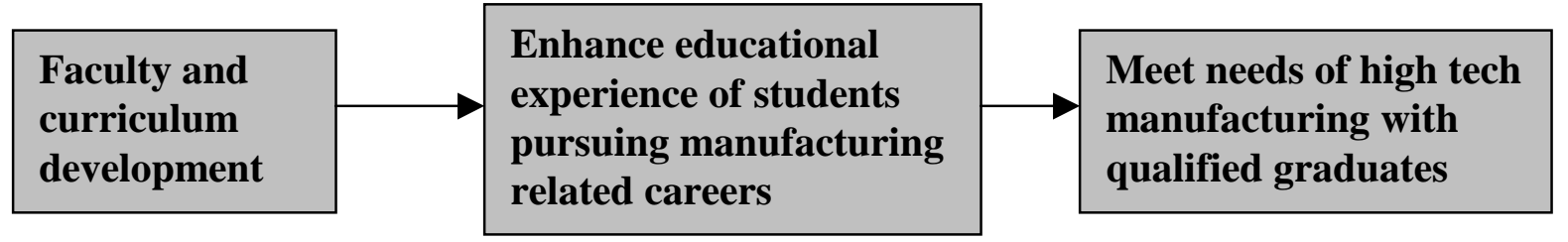

In the scope of this project, the second and third goals are a result of the first goal. Therefore, evaluation activities must first assess the faculty and curriculum development aspects of this project before meaningful data can be collected on how this impacts the educational experiences of students and subsequently, how this is meeting the human resource needs of high-tech manufacturing.

Broadly speaking, training, education, and development activities such as this intend to improve knowledge, skills, attitudes, and performance in present and future roles. Evaluation of our faculty and curriculum development activities will serve the role of determining the extent to which knowledge, skills, attitudes, and performance have been improved. "Finding out what has worked and what has not is essential for human performance improvement and organization success. Without evaluating, we don't know which performance intervention to stop, modify, continue or improve." The evaluation charter in an educational, training or development organization serves as the quality control system.

Kirkpatrick (1959) recommends the use of the following four types of data to garner meaningful evaluation information: reaction, learning, behavior, and results. The Kirkpatrick taxonomy originated in 1952 and has been widely utilized by the private sector to evaluate training and development programs. "The model doesn't provide details on how to implement all four levels. Its chief purpose is to clarify the meaning of evaluation and offer guidelines on how to get started and proceed.",2

The first tier in the taxonomy, called the reactionary level, is designed to garner information about how the participants feel about the training. Critical questions addressed with these evaluation efforts are as follows. How well did the participants like the workshop? Is there anything that can be improved? Did the workshop modify beliefs, convictions, or attitudes in any way? More favorable reactions indicate, but do not guarantee, that participants are more likely to have learned more. Reaction data are utilized primarily in the formative stages to make improvements. Reaction data do not provide enough information for the evaluator to make any summative conclusions about program effectiveness. 
To garner reaction information, questionnaires were administered at each workshop. A miniquestionnaire was administered at the end of each day of the workshop. The purpose of this daily questionnaire was to gather information on the content and conduct of the workshop to be utilized for immediate improvement. A more detailed final questionnaire was then administered at the end of the workshop. The purpose of the final questionnaire was to gather more detailed information on the content and conduct of the workshop, as well as to gather information on communication, expectations, and facilities.

The second level of evaluation is termed the learning level. Evaluation at this level is a "measure of the knowledge acquired, skills improved, or attitudes changed due to training." 2 Critical questions asked when evaluating learning include the following. What principles, facts and techniques were learned? Can participants demonstrate what they learned in an observable manner? How and why did learning occur? If learning did not occur, why not? How can the training be improved to enhance learning? Information gathered regarding participants' learning can be used both formatively and summatively, depending upon the original purpose of the training/development event.

For the MCATE project as a whole, the data collected will be used to improve the effectiveness of the workshops. In the scope of a single workshop, 1998 and 1999 participants will have the option of taking the workshop for a grade. In this case, the learning data may be used summatively to assign a grade.

To measure the amount of learning that took place, MCATE participants are required to transform what they have learned into curriculum materials that they will share with MCATE. In addition, pretest data regarding skills and knowledge were collected through a self-report questionnaire administered prior to the workshop. Posttest data will be collected through a selfreport questionnaire in the spring of 1998.

The third tier in the evaluation plan is called the behavioral level. Behavioral outcomes can be referred to as transfer of training. The evaluation activities employed at this level are targeted at determining the following. What changes in job behavior resulted from the workshop? Are the participants applying what they learned? Why or why not? Again, information is gathered for both formative and summative purposes. Data gathered regarding why, why not or how participants are applying what they learned can be used to make program improvements to affect impact. Information gathered about changes in job behavior and application of what was learned can provide summative information about the impact of the training event.

In the scope of MCATE, it is necessary to collect data on how participants are implementing materials provided at the workshop as well as the materials they authored as a result of the workshop. Again, pre and post data regarding implementation are being collected. Pre data for the 1997 workshops have been collected and post data will be collected in the spring of 1998. Changes in job behavior can also extend beyond the scope of the training event. In this regard, changes are an ongoing outgrowth of training. As outcomes become less directly tied to the training event, they become more difficult to measure and more subject to other intervening variables. MCATE will be collecting data on subsequent outgrowths in the spring of 1998. 
Currently, this is the only interval at which post data will be collected on subsequent outgrowths due to the concern of intervening variables.

The final evaluation tier is the results level. Results evaluation intends to measure how training is affecting the organization or entity. The critical questions to be answered at this level are as follows. What are the final results due to the training/development? What impact has the MCATE faculty/curriculum development project had on enhancing student learning and on meeting the human resource needs of high tech manufacturing? How did the MCATE faculty/curriculum development project accomplish this impact? Data gathered with the intent of providing results information is primarily considered summative data since it is assessing and reporting outcomes and impacts. The evaluation process is cumulative in nature. As reaction data alone are limited in utility, so too are outcomes data. "Where outcomes are evaluated without knowledge of implementation, the results seldom provide a direction for action because the decision maker lacks information about what produced the observed outcomes."3 Data at this level is often hard to collect and has the potential to be influenced by many factors external to the project.

At this point in time, it is expected that outcomes data will be collected through document analysis, post questionnaire surveys, interviews with participating faculty, and classroom observations. To collect data from the manufacturing sector, MCATE plans to utilize focus group interviews with our Industrial Advisory Council and National Visiting Committee members. Outcomes data will be collected for each round of workshops and analyzed collectively to formulate summative information about the program's impact.

\section{$\underline{\text { Teacher Perspective }}$}

From the workshop developer/facilitator perspective, MCATE provides an excellent foundation in the needed administration and management of the overall workshop process. MCATE not only provided the opportunity to produce and provide these workshops; but MCATE also developed, marketed, administered, and evaluated the entire process, handling a myriad of details. This left the developers of the workshops unfettered in focusing their creative efforts on the workshops. This effective division of effort was invaluable in producing a quality program.

MCATE is providing the forum for the development of needed technology workshops that might not otherwise exist. Even though there is a need for such workshops, there must be a mechanism to create these workshops with the appropriate resources. The synergy of combining the resources, a management team, workshop developers, and attendees makes the difference in facilitating this technical education network development and expansion. The outcome is an expanding network of technology educators who impact their environment and in turn enhance MCATE itself and the National Science Foundation ATE Program.

MCATE provides an additional avenue to reach out to faculty who might not otherwise be able to participate in current technology education workshops. Many educational institutions do not have the financial resources to bring in workshops of this quality nor to send faculty to such workshops. The partnership of many institutions and the initial sponsorship of NSF provide the 
catalyst to initiate a program that has the potential to have a profound impact on many faculty regionally, and eventually nationally.

\section{$\underline{\text { Future Directions }}$}

In an effort to provide high tech manufacturing with skilled graduates, MCATE will expand its activities geared toward providing faculty and curriculum development to educators who are preparing students for these manufacturing related careers. We will be sponsoring 10 workshops in 1998 and 1999, and pursuing internship opportunities in industry for faculty and students, both of which will result in curriculum development and implementation into the classroom. While we believe that such initiatives are an excellent beginning, we believe that in order to sustain progress, faculty and curriculum development opportunities need to benefit not only the student, but also the faculty member. Hence, we will be pursuing faculty/curriculum development opportunities through a variety of delivery mechanisms and methods with the possibility of earning continuing education units and/or credit potentially leading to another degree.

Bibliography

1. Kaufman, R., Keller, J., and Watkins, R. (1995). What works and what doesn't: evaluation beyond kirkpatrick. Performance Improvement Quarterly, Vol. 35, No. 2.

2. Kirkpatrick, D. (1996). Great ideas revisited, Training and Development, Vol. 50, No. 1.

3. Patton, M. Q. (1990). Qualitative Evaluation and Research Methods, Sage, Newbury Park, CA.

Biographical Information

MELISSA J. DARK is the Assistant Director of MCATE and a doctoral student in the School of Education, Purdue University. Research interests include instructional research and development and educational evaluation. Professional memberships include AEA, AERA, ITEA and ASEE.

DENNIS R. DEPEW is currently the Head of the Department of Industrial Technology, and Director of Graduate Studies for the School of Technology. He is also Coordinator of the Excellence 21 program, and the Director of the Midwest Center for Advanced Technology Education. In addition to his administrative responsibilities, Dennis continues to teach a course in Quality and Productivity Improvement and Engineering Economics in the School of Technology.

ROBERT J. HERRICK is a Professor and Assistant Department Head for the Department of Electrical Engineering Technology, School of Technology, Purdue University. He is a Purdue Teaching Academy charter member and executive board member and the recipient of departmental, school, and professional society teaching awards. Professional memberships include Tau Beta Pi, IEEE Press, Editorial Board, IEEE Press, Series Editor, and ASEE. 